\title{
The Role of Muscarinic and Nicotinic Cholinergic Neurotransmission in Aversive Conditioning: Comparing Pavlovian Fear Conditioning and Inhibitory Avoidance
}

\author{
Matthew R. Tinsley, ${ }^{1}$ Jennifer J. Quinn, and Michael S. Fanselow \\ Department of Psychology, University of California, Los Angeles, California 90095, USA
}

Aversive conditioning is an ideal model for studying cholinergic effects on the processes of learning and memory for several reasons. First, deficits produced by selective lesions of the anatomical structures shown to be critical for Pavlovian fear conditioning and inhibitory avoidance (such as the amygdala and hippocampus) resemble those deficits seen in human pathological conditions resulting in damage to these same structures. This supports the suggestion that experimental findings on learning and memory in animal models are informative about similar processes in humans. Second, because aversive conditioning is learned rapidly, even with a single conditioning trial, the temporal dynamics of the underlying processes can be examined with a very fine degree of resolution. Third, the fear memories generated by aversive conditioning procedures tend to be very stable over long time periods. For example, we have observed robust freezing to both tone and context up to 16 mo following fear conditioning (Gale et al. 2003). Finally, fear is a motivational system that has evolved to protect an animal from danger. Fear responses observed under laboratory conditions are similar to those observed in the animal's natural habitat, meaning that the results of aversive conditioning procedures typically have external validity.

Pavlovian Fear Conditioning and Inhibitory Avoidance: Procedures and Neural Substrates

Although a variety of conditioning procedures have been used to examine cholinergic effects on aversive conditioning, the two most popular recently have been Pavlovian fear conditioning and inhibitory, or passive, avoidance. In Pavlovian fear conditioning procedures, the animal is placed in a conditioning context and a previously neutral stimulus such as a tone (the conditional stimulus, CS) is paired with an aversive stimulus such as electric shock (the unconditional stimulus, US). As a result of the pairing of tone and context with shock, both the tone and context acquire the ability to elicit a defensive behavioral response such as freezing (the conditional response, CR) during reexposure. In a typical inhibitory avoidance procedure, the animal is placed into a chamber with two separate compartments. One compartment is brightly lit while the other is dimly lit. The animal is placed into the bright compartment, and the latency to enter the dim compartment is recorded. After the animal enters the dim compartment, the passageway is closed and the animal receives inescapable footshock. On a subsequent test day, the

\footnotetext{
'Corresponding author.

E-MAIL mtinsley@psych.ucla.edu; FAX (310) 206-5895.

Article and publication are at http://www.learnmem.org/cgi/doi/10.1101/ Im.70204.
}

animal is replaced in the bright compartment, and its latency to enter the dim compartment is recorded.

It is clear that these two training procedures have much in common. In both cases, the animal experiences a pairing of a previously neutral stimulus, context or tone, with shock. In each case, it is likely that Pavlovian conditioned associations between the context and shock influence subsequent behavior. However, there are also important differences between these two procedures. In Pavlovian fear conditioning, the presentation of shock is independent of the animal's behavior: The contingency between the CS and US is determined by the experimenter. In inhibitory avoidance training, however, the animal must make a response, entering the dim chamber, before being shocked. As a result, it is likely that the footshock acts both to condition the dimly lit compartment as an aversive contextual CS through Pavlovian conditioning processes and to punish the behavior of entering the dim compartment through operant conditioning processes. The requirement of an instrumental response not only differentiates the nature of the psychological processes examined in Pavlovian fear conditioning and inhibitory avoidance but may also have effects on the neural substrates involved (see below and Maren 2003 for a recent discussion of this point). Furthermore, because frightened animals have a dark preference, inhibitory avoidance places animals in a conflict situation, which may recruit additional neural processes. Thus, despite their superficial similarity, inhibitory avoidance is a much more complex, and poorly understood, task than Pavlovian fear conditioning.

The underlying neural circuitry of Pavlovian fear conditioning has been examined extensively using a variety of fear responses (for review, see Fendt and Fanselow 1999) and has been demonstrated to include the amygdala, hippocampus, and frontal cortex, depending on procedure. The frontotemporal amygdala (the lateral and basolateral nuclei; Swanson and Petrovich 1998 ) is critical for both the acquisition and expression of conditional fear (see Maren and Fanselow 1996 for review). Pre- or posttraining lesions of the frontotemporal amygdala (FTA) eliminate conditional fear (LeDoux et al. 1988; Davis 1992; Maren et al. 1996b). FTA inactivation (Helmstetter and Bellgowan 1994; Muller et al. 1997) or blockade of $N$-methyl-D-aspartate (NMDA) receptor activity within the FTA (Maren et al. 1996a; Lee et al. 2001) also blocks the acquisition and expression of contextual and cued fear conditioning. This series of findings has led to the conclusion that this component of the amygdala is involved in both the neural encoding and storage of Pavlovian conditioned fear memories (Fanselow and LeDoux 1999).

Evidence from inhibitory avoidance studies indicates a potentially different role for the amygdala (McGaugh et al. 1996, 2000; Cahill and McGaugh 1998). Cahill and McGaugh (1990) 
showed that large pretraining lesions of the amygdala attenuate, but do not block, inhibitory avoidance learning. Additionally, posttraining amygdala lesions do not block inhibitory avoidance retention (Parent et al. 1992, 1994, 1995; Parent and McGaugh 1994). Although these results contrast with those from Pavlovian fear conditioning described above, they are consistent with results from other procedures that include a component of instrumental conditioning. Schafe et al. (1998) have demonstrated that lesions of the FTA affect conditioned taste aversion learning when the taste CS is simply presented but not when CS presentation is contingent on the animal completing an instrumental response. More recently, Lehmann et al. (2003) have demonstrated that inactivations of the BLA with tetrodotoxin during shock probe training reduces subsequent avoidance of the probe. Killcross et al. (1997) have also demonstrated differential roles of amygdala nuclei in conditioned suppression and active avoidance, further indicating that the role of the amygdala may be different in instrumental and Pavlovian tasks. These findings, and the greater inherent complexity of the inhibitory avoidance task, indicate that the role of the amygdala in Pavlovian fear conditioning and inhibitory avoidance may well differ. Given the extensive literature on intra-amygdala cholinergic manipulations in inhibitory avoidance and the different effects of cholinergic manipulations in studies using inhibitory avoidance and Pavlovian fear conditioning (described below), this procedural difference should be an important caveat to any general conclusions about the role of cholinergic transmission in aversive learning and memory.

The hippocampus is necessary for contextual and trace tone fear conditioning, but not for delay tone conditioning (e.g., Kim and Fanselow 1992; Phillips and LeDoux 1992; Quinn et al. 2002). Infusions of either NMDA or acetylcholine receptor antagonists into the hippocampus during training have revealed learning deficits in context but not delay tone fear conditioning (e.g., Young et al. 1994; Gale et al. 2001). In addition, lesions of the hippocampus following training produce a temporally graded retrograde amnesia for contextual fear conditioning (e.g., Kim and Fanselow 1992; Anagnostaras et al. 1999a). This pattern of results, as well as a substantial body of additional literature, has led to the suggestion that the role of the hippocampus in Pavlovian fear conditioning is to form representations of certain classes of CS rather than in the formation of the CS-US association (Maren and Fanselow 1995; Fendt and Fanselow 1999).

Hippocampal involvement in inhibitory avoidance seems to show a pattern largely consistent with that in Pavlovian context conditioning. Pre- and posttraining lesions of the dorsal CA1 field or ventral CA3 field reduce consolidation of inhibitory avoidance learning (Martinez et al. 2002). Similarly, posttraining infusions of the protein kinase A inhibitor Rp-cAMPs, the calcium-calmodulin kinase II inhibitor $\mathrm{KN}-62$, and the NMDA receptor antagonist AP5 all reduce consolidation of inhibitory avoidance learning (Vianna et al. 2001). Additionally, posttraining infusion studies indicate that the hippocampus is involved in consolidating contextual but not aversive aspects of inhibitory avoidance training. Pre-exposure to the training context blocks the impairing effect of posttraining intrahippocampal infusion of AP5, but not the impairing effect of posttraining intraamygdala AP5, indicating that the hippocampus is needed to form the context representation and not the aversive association (Roesler et al. 2003).

More recently, researchers have been investigating the potential role(s) of various cortical regions in Pavlovian fear conditioning. We have recently shown that excitotoxic lesions within the anterior cingulate cortex of mice produce similar deficits in trace fear conditioning, while leaving delay fear conditioning intact (Han et al. 2003). Sacchetti et al. (2002) have found that lidocaine inactivation of the perirhinal cortex $3 \mathrm{~h}$ posttraining impaired consolidation of fear conditioning to both a delay tone and contextual CS. Prefrontal cortex inactivation enhanced consolidation of both memories, whereas infusions into frontal and parietal cortices attenuated consolidation of conditioned fear to a delay tone CS but not a contextual CS. Inactivation of all four sites $72 \mathrm{~h}$ following training led to consolidation deficits. A similar study performed using tetrodotoxin inactivation (Sacchetti et al. 2003) demonstrated parietal cortex infusions attenuated delay tone, but not context, fear when performed $15 \mathrm{~min}$ or $24 \mathrm{~h}$ following Pavlovian fear conditioning but that frontal cortex inactivations were only effective in blocking tone consolidation if given immediately after training.

Inhibitory avoidance, too, seems to involve various cortical regions. Posttraining infusions of AP5, the dopamine D1 antagonist SCH23390 and the $\mathrm{GABA}_{\mathrm{A}}$ agonist muscimol into the precentral prefrontal cortex all block consolidation of inhibitory avoidance (Mello e Souza et al. 2000). Baldi et al. (2000) investigated the role of circuitry involving the perirhinal cortex during consolidation of inhibitory avoidance using tetrodotoxin inactivations of perirhinal cortex and either the medial septal area, the fimbria-fornix, or the entorhinal cortex. They found that all three treatments given immediately following training impaired consolidation of inhibitory avoidance.

Finally, there is a substantial body of literature from inhibitory avoidance studies indicating a role for the dorsal striatum in the consolidation of aversive conditioning (e.g., Prado-Alcala et al. 1993). Lesions and inactivation of the dorsal striatum have been shown to affect learning and memory for inhibitory avoidance (Winocur and Mills 1969; Glick et al. 1974; Prado-Alcala et al. 1975). Salado-Castillo et al. (1996) demonstrated that posttraining infusion of GABAergic drugs into various regions of the dorsal striatum interfered with memory consolidation following inhibitory avoidance training. Similar effects have been found recently following a variety of serotonergic manipulations (Solana-Figueroa et al. 2002; Prado-Alcala et al. 2003a,b). The effects of intrastriatal cholinergic manipulations on inhibitory avoidance will be discussed below.

A literature is beginning to develop on the effects of striatal manipulations on Pavlovian fear conditioning. Ferreira et al. (2003) examined the effects of pretraining electrolytic and excitotoxic anterodorsal striatum lesions on delay tone and contextual fear conditioning. They found deficits in tone, but not context, conditioning following both electrolytic and excitotoxic lesions when animals were tested $14 \mathrm{~d}$ following surgery but not when animals were tested $60 \mathrm{~d}$ after surgery, implying a timelimited role in consolidation similar to that observed in the hippocampus (e.g., Kim and Fanselow 1992; Anagnostaras et al. 1999a). White and Salinas (2003) examined the effect of posttraining amphetamine infusions into dorsal striatum or hippocampus. They found that posttraining amphetamine infusions into the striatum facilitated subsequent freezing to both contextual and delay tone cues. Clearly, further study on the role of the dorsal striatum in Pavlovian fear conditioning is required to determine its similarity to that shown in inhibitory avoidance.

In conclusion, there are important similarities between Pavlovian fear conditioning and inhibitory avoidance. Both are rapidly acquired, aversively motivated forms of learning that use heavily overlapping neural substrates. In most cases, and to the extent that they have been examined, these substrates perform the same functions in each task. There are, however, important differences between these tasks that seem to be related to the additional complexity of inhibitory avoidance. For one, the role of the amygdala in inhibitory avoidance differs in a manner that is somewhat consistent with other forms of amygdala-modulated learning that include an operant requirement (Maren 2003). 
Given the importance of the amygdala in cholinergic modulation of aversive learning, this distinction is likely to prove necessary for a complete understanding of the role of acetylcholine in these procedures.

\section{Basal Forebrain Lesions and Pavlovian Fear Conditioning}

The "basal forebrain" is the major source of cholinergic innervation to an array of forebrain structures known to be involved in aversive conditioning, including the amygdala, hippocampus, and frontal cortex. Within the basal forebrain, the predominant cell types are cholinergic and GABA-ergic neurons, with a lesser number of smaller peptidergic neurons. Within the continuum of basal forebrain regions, two areas have been investigated most extensively because of their discrete projections. The nucleus basalis magnocellularis (nBM) projects to the frontal cortex and the frontotemporal amygdala, whereas the medial septal area (MSA) projects to the hippocampus (for a review of central cholinergic projections, see Everitt and Robbins 1997).

Until recently, it has been difficult to selectively affect cholinergic transmission with lesions of the basal forebrain owing to the lack of spatial separation between differing populations of neurons. Excitotoxic lesions of the basal forebrain using a variety of techniques alter cholinergic activity in the various terminal fields. However, these effects are confounded with alterations in other neurotransmitter systems caused by the loss of noncholinergic cell bodies. Despite this lack of selectivity, excitotoxic lesions of the basal forebrain have demonstrated effects on Pavlovian fear conditioning. McAlonan et al. (1995) investigated the effects of AMPA-induced lesions of the septohippocampal projection on Pavlovian trace fear conditioning and found a decrease in trace tone conditioning at longer, but not shorter, trace intervals. Schauz and Koch (1999) investigated the effects of quinolinic acid lesions of the $\mathrm{nBM}$, a procedure demonstrated to cause damage to the cholinergic innervation of the amygdala, on latent inhibition (LI) of fear-potentiated startle. They found no effect of lesions in their non-LI group, indicating that disruptions of cholinergic transmission in the amygdala do not affect the Pavlovian delay fear conditioning used in fear-potentiated startle.

With the advent of the selective cholinergic immunotoxin 192 IgG-saporin, lesions can be made within the basal forebrain that produce massive degeneration of cholinergic input specifically (e.g., Baxter et al. 1995). Conner et al. (2003) compared the effects of combined nBM and MSA lesions on delay tone fear conditioning and found no effect of the lesion on activity suppression caused by presentations of the CS in a novel context. Unfortunately, they did not test the effects of these lesions on contextual fear.

The effects of medial septal cholinergic cell body lesions are largely consistent with the effects of hippocampal lesions in affecting trace tone, and not delay tone, conditioning. Further studies are required to determine whether cholinergic selective lesions, like excitotoxic hippocampal lesions, affect context conditioning. Additional studies are also required to determine whether these lesions show the same temporally graded effects on consolidation as posttraining hippocampal lesions. Although the lack of an effect of quinolinic acid lesions of the nBM on the acquisition of conditional fear, as measured with fearpotentiated startle (Schauz and Koch 1999), is surprising given their effect on cholinergic afferents to the amygdala, further study with selective immunotoxin may be required to determine that cholinergic transmission in the amygdala is not involved in delay fear conditioning. In addition, it would be interesting to determine $\mathrm{nBM}$ cholinergic lesions disrupt trace tone conditioning, as recent evidence indicates frontal cortex involvement in this procedure.

\section{Basal Forebrain Lesions and Inhibitory Avoidance}

Basal forebrain lesion studies have also been performed in inhibitory avoidance studies. Power and McGaugh (2002) used the nonselective excitotoxin phthalic acid, which has been shown to reduce choline acetyltransferase activity in the amygdala more than in the cortex (Mallet et al. 1995), to unilaterally lesion the nBM-FTA cholinergic pathway prior to training. They found that phthalic acid-lesioned animals showed significantly reduced inhibitory avoidance learning. This reduction could be rescued with ipsilateral infusions of the muscarinic agonist oxotremorine or the acetylcholinesterase inhibitor physostigmine into the FTA. Lesioned rats also showed slowed acquisition when trained on a continuous multiple-trial version of the inhibitory avoidance task and reduced memory consolidation when tested $48 \mathrm{~h}$ after this training. Hence, these results indicate effects on both rate of acquisition and consolidation.

The same group has also investigated the effects of the acetylcholine-selective immunotoxin 192 IgG-saporin (see also Zhang et al. 1996). Power et al. (2002) lesioned the nBM $8 \mathrm{~d}$ prior to inhibitory avoidance training and compared the effects of posttraining intra-amygdala norepinephrine infusions on subsequent inhibitory avoidance performance. Unlike pretraining phthalic acid lesions, saporin lesions had no effect on inhibitory avoidance learning. They did, however, block the enhancing effect of posttraining norepinephrine infusions. This lack of an effect with 192 IgG-saporin lesions may be due to the immunotoxin's selective effect on cortical projections and comparative lack of effect on amygdalopetal cholinergic projections (Power et al. 2003).

\section{Pharmacological Muscarinic Manipulations and Pavlovian Fear Conditioning}

Results from studies of pharmacological muscarinic cholinergic manipulations on Pavlovian fear conditioning show inconsistent effects, with muscarinic receptor activation being implicated in both the acquisition and consolidation of contextual, but not delay tone, fear conditioning. Pretraining injections of the muscarinic cholinergic antagonist scopolamine reduce acquisition of contextual fear conditioning in rats (Anagnostaras et al. 1995, 1999b), at a dose that did not affect simultaneously conditioned delay tone fear, in a procedure using multiple conditioning trials. Immediate and $24 \mathrm{~h}$ posttraining manipulations in both adult and juvenile (20-25 day old) animals in these studies have no effects, indicating cholinergic involvement in acquisition, but not consolidation (Anagnostaras et al. 1999b). In contrast, and using juvenile (23 day old) rats, Rudy (1996) found that injections of scopolamine either before or up to $3 \mathrm{~h}$ after Pavlovian fear conditioning disrupted both tone and context conditioning when a single training trial was given, also indicating muscarinic cholinergic effects on memory consolidation. However, when multiple training trials were given, no posttraining effect was found on tone fear.

These results indicate that a crucial factor in determining how systemic muscarinic cholinergic treatment affects Pavlovian fear conditioning is the number of training trials given in a session. In those cases in which multiple trials are given, there is either no effect (Anagnostaras et al. 1995, 1999b) or a diminished effect (Rudy 1996) of posttraining muscarinic antagonism (but see Wallenstein and Vago 2001). In contrast, where a single shock presentation is used (Rudy 1996), posttraining muscarinic blockade does influence memory consolidation. This distinction may also help to explain the differences between Pavlovian conditioning results and inhibitory avoidance studies, which typically find posttraining effects and generally use a single shock procedure (see below). 
The effects of muscarinic antagonism on Pavlovian fear conditioning may be due to alterations in the muscarinic M1 receptor function. Fornari et al. (2000) examined the effect of a range of pretraining doses of the M1 muscarinic antagonist dicyclomine on the acquisition of fear conditioning and inhibitory avoidance. Consistent with previous studies using scopolamine, pretraining systemic injection with dicyclomine dosedependently impaired contextual fear conditioning without affecting cued fear conditioning. Unfortunately, because the study did not include posttraining manipulations, it cannot be determined whether this is an effect on acquisition or consolidation of the fear memory.

The effects of central administration of muscarinic agents are also consistent with an effect on consolidation of Pavlovian contextual fear conditioning. Pretraining scopolamine infusions into the dorsal hippocampus block the acquisition of contextual fear conditioning (Gale et al. 2001; Wallenstein and Vago 2001). However, posttraining infusions have a similar effect (Wallenstein and Vago 2001), implying that this effect may be on consolidation. Posttraining intra-amygdala infusion of the muscarinic agonist oxotremorine enhances consolidation of contextual fear conditioning (Cangioli et al. 2002), whereas administration of scopolamine disrupts it (Passani et al. 2001). Posttraining intra-amygdala infusion with a histaminergic $\mathrm{H}_{3}$ agonist or antagonist, which decrease and increase cholinergic tone in the amygdala, respectively (Passani et al. 2001; Cangioli et al. 2002), have also been shown to affect long-term memory for contextual fear conditioning, potentially through the same muscarinic receptordependent mechanisms (Passani et al. 2001; Cangioli et al. 2002).

Comparatively little has been published on the effects of muscarinic manipulations on the retrieval of Pavlovian conditioned fear memories. Greba et al. (2000) used a fear-potentiated startle procedure to determine the effect of intraventral tegmental area (VTA) administration of a muscarinic antagonist. They found that infusions of the muscarinic antagonist methylscopolamine into the VTA disrupt fear potentiation of startle without affecting baseline startle amplitude. This may indicate that muscarinic cholinergic modulation of dopaminergic activity may be involved in mediating recall for fear memories by modulating dopamine release in the amygdala (Greba et al. 2000).

\section{Pharmacological Muscarinic Manipulations and Inhibitory Avoidance}

There is a long history of investigating the effects of muscarinic cholinergic manipulations on learning and memory using inhibitory avoidance (e.g., Meyers 1965; for reviews, see Bammer 1982; Prado-Alcala 1995; Power et al. 2003). These studies have typically used posttraining manipulations, focusing on effects on memory consolidation and avoiding the possibility of confounding these effects with those on acquisition and expression (McGaugh 1966). It has been reported that posttraining cholinergic and muscarinic agonist injection enhances performance of inhibitory avoidance (Baratti et al. 1979) and that central muscarinic antagonist treatment has the opposite effect (Izquierdo et al. 1992). Researchers have also used receptor-selective systemic treatments to further investigate the mechanisms underlying these effects. Pretraining administration of relatively selective muscarinic M1 receptor antagonists such as pirenzepine (Caulfield et al. 1983; Worms et al. 1989) and dicyclomine (Fornari et al. 2000) impair performance of inhibitory avoidance. Posttraining systemic administration of M1 antagonists such as biperidine and trihexyphenidyl (Roldan et al. 1997) or dicyclomine (Giachetti et al. 1986) also impair performance of inhibitory avoidance, indicating that the effect of M1 antagonism may be an impairment of memory consolidation.
Central manipulations in the hippocampus, cortex, amygdala, and striatum have also demonstrated cholinergic effects on inhibitory avoidance. Hippocampal infusions of the muscarinic agonist oxotremorine or muscarinic toxins with M1-agonist-like properties in the hippocampus enhance retention of inhibitory avoidance (Izquierdo et al. 1992; Jeruzalinsky et al. 1993) that can be blocked by scopolamine (Jeruzalinsky et al. 1993). Similar effects have been found in the anterior cingulate cortex, with posttraining scopolamine infusions impairing performance of inhibitory avoidance (Riekkinen et al. 1995).

There is a much more extensive literature on cholinergic effects in the amygdala with posttraining intra-amygdala infusion of the muscarinic antagonist scopolamine attenuating performance of inhibitory avoidance (Izquierdo et al. 1992; for review, see Power et al. 2003) and treatment with the muscarinic agonist oxotremorine enhancing inhibitory avoidance, an effect that is blocked by coinjection of atropine (Introini-Collison et al. 1996). Studies focusing on other transmitter systems have also shown effects consistent with the primary role of amygdala muscarinic receptors in memory consolidation. Intra-amygdalar $\beta$-adrenergic, opiate antagonist, and glucocorticoid enhancement of memory consolidation are all blocked by doses of atropine that have no effect on their own (Introini and Baratti 1984; Dalmaz et al. 1993; Power et al. 2000).

There is also a substantial body of research on the role of intrastriatal cholinergic manipulations affecting consolidation of inhibitory avoidance (for review, see Prado-Alcala 1995). Posttraining intra-striatal muscarinic blockade attenuates performance of inhibitory avoidance (Haycock et al. 1973), an effect that can be reduced by striatal coadministration of choline (Solana-Figueroa and Prado-Alcala 1990). These effects of intrastriatal cholinergic antagonists on memory consolidation are highly dependent on training parameters and shock intensity in particular. Using high levels of shock intensity protected inhibitory avoidance consolidation from the disruptive effects of posttraining intrastriatal atropine (Giordano and Prado-Alcala 1986).

\section{Pharmacological Nicotinic Manipulations and Pavlovian Fear Conditioning and Inhibitory Avoidance}

There is a wealth of literature showing nicotinic effects on a variety of cognitive functions, including working memory (Poincheval-Fuhrman and Sara 1993; Levin 2002), spatial learning (Bernal et al. 1999), and covert attention (Stewart et al. 2001). Early studies on the role of nicotinic manipulations in aversive conditioning used active avoidance (e.g., Bovet et al. 1966; Oliverio 1966) and there remain comparatively few studies that have examined effects of pharmacological nicotinic manipulations on the acquisition and consolidation of Pavlovian fear conditioning and inhibitory avoidance.

Systemic, acute pretraining injections of nicotine, the archetypal agonist at nicotinic receptors, 5 to $20 \mathrm{~min}$ prior to Pavlovian fear conditioning in rats, reduce levels of context fear during a subsequent test session (Szyndler et al. 2001). These effects are not caused by unconditional increases in freezing caused by the nicotine injection itself or are the result of changes in pain sensitivity. However, no posttraining injection of nicotine was given, making it impossible to determine whether this effect was on acquisition or consolidation of fear conditioning. This behavioral effect is not present in animals receiving six daily nicotine injections prior to training (Szyndler et al. 2001), indicating that they become tolerant to the effects of systemic nicotine.

Gould and Wehner (1999) also examined the effects of systemic nicotine on Pavlovian fear conditioning in mice. They found that nicotine given on acquisition and retrieval (but not 
on acquisition or retrieval alone) enhances contextual but not cued fear conditioning (Gould and Wehner 1999). Treatment with the nicotinic antagonist mecamylamine on both the training and test days blocked this nicotine effect but had no effect when administered alone. They suggested that this result may potentially be due to a state-dependency of learning effect similar to that found with nicotine in humans (Warburton et al. 1986). Gould and Higgins (2003) have subsequently found that nicotine treatment prior to training and test, but not training or test alone, enhanced conditioning, replicating the findings of Gould and Wehner (1999). Additionally, animals treated with nicotine prior to training and test showed enhanced conditioning $7 \mathrm{~d}$ after training during a drug-free test, indicating that this enhancement was not due to state-dependency. This effect was not seen in animals that received nicotine prior to training and received nicotine the following day but without a test of conditioned fear, indicating that the enhancement may involve retrieval processes.

Posttraining intracerebroventricular infusions of acetylcholine or nicotine have been shown to enhance inhibitory avoidance. This effect is reduced by coinfusion of histamine or scopolamine (Eidi et al. 2003). Developmental studies have indicated a role of amygdala nicotinic receptors with pretraining nicotine infusions enhancing inhibitory avoidance when delivered on postnatal day 20 . Pretraining amygdala mecamylamine infusions attenuated inhibitory avoidance conditioning from postnatal day 11, showing their strongest effects at day 16 and waning from that point forward (Blozovski and Dumery 1987). There is also evidence of nicotinic effects on memory retrieval from inhibitory avoidance studies. Systemic nicotine administration 15 min prior to a retrieval test increased inhibitory avoidance (Zarrindast et al. 1996). This effect was opposed by the centrally acting antagonist mecamylamine but not the peripherally acting antagonist hexamethonium or the muscarinic antagonist atropine.

\section{Genetic Muscarinic Manipulations and Effects on Pavlovian Fear Conditioning}

Genetic manipulations have also been used to examine the role of the muscarinic cholinergic system in Pavlovian fear conditioning, but not yet on inhibitory avoidance. Miyakawa et al. (2001) reported on an M1 receptor knockout mouse that showed reduced freezing during delay fear conditioning and a subsequent tone test, but normal levels of context fear when tested $24 \mathrm{~h}$ later. However, when tested 4 wk after training, the M1 knockout mice showed significantly less freezing than wild-type controls across the duration of the test.

Anagnostaras et al. (2003) investigated another strain of M1 receptor knockout mice. They found a complex pattern of effects on learning and memory without changes in overall levels of activity or shock reactivity. When mice were tested $24 \mathrm{~h}$ following training, the M1 knockout mice showed enhanced contextual and normal delay tone memory. However, when the animals were tested $30 \mathrm{~d}$ after conditioning, M1 knockout mice showed impaired contextual conditioning and normal delay tone memory. Based on these data, and data from other behavioral tasks they report in this paper, Anagnostaras et al. (2003) conclude that M1 knockout mice show a deficit in hippocampalcortical interaction that manifests in tests of Pavlovian conditioning as impaired consolidation of contextual memory. They suggest that this deficit is not simply mnemonic but, instead, represents a general biasing of hippocampal function toward acquisition of new information and away from recall of previously acquired information (Hasselmo 1999; Fransen et al. 2002).

\section{Genetic Nicotinic Manipulations and Pavlovian Fear Conditioning and Inhibitory Avoidance}

Mice with reduced function of two classes of nicotinic receptor subunits, the $\alpha 7$ and $\beta 2$ subunits, have been assessed for changes in aversive conditioning. Mice homozygous for knockout of the $\alpha 7$ receptor subunit showed no differences in either context or tone fear following delay fear conditioning, compared with wildtype controls (Paylor et al. 1998). Calderone et al. (2000) determined that aged (9-20 month old) male but not female or young (2-4 month old) $\beta 2$ knockout mice displayed deficits in context and tone fear following delay fear conditioning. They concluded that under normal circumstances, nicotinic receptors containing $\beta 2$ subunits are not required for normal performance in Pavlovian fear conditioning.

Picciotto et al. (1995) examined the effects of $\beta 2$ knockout on inhibitory avoidance and found that whereas mutant animals showed enhanced inhibitory avoidance, unlike wild-type animals they failed to show a facilitation of consolidation following posttraining nicotine injection. Recently this group has examined this effect more closely using transgenic mice with regionally and temporally restricted expression of the $\beta 2$ receptor subunit (King et al. 2003). They found that mice that express the $\beta 2$ receptor subunit only in cortex and thalamus show normal levels of inhibitory avoidance, and significantly less inhibitory avoidance than $\beta 2$ knockout mice. Subsequently, they examined whether $\beta 2$ expression in cortex and thalamus was necessary for normal acquisition of inhibitory avoidance by using a doxycycline-inducible knockout of the $\beta 2$ receptor subunit gene and found that this manipulation did not affect learning and performance of inhibitory avoidance despite the absence of the $\beta 2$ subunit. They concluded that the effect of $\beta 2$ receptor subunit knockout on inhibitory avoidance is caused by developmental effects possibly related to the development of glutamatergic synapses.

\section{Conclusions}

Manipulations of muscarinic and nicotinic cholinergic neurotransmission have been demonstrated to affect every aspect of aversive conditioning. Pharmacological experiments have demonstrated effects on acquisition, consolidation, and retrieval of both muscarinic and nicotinic pharmacological treatments. Genetic manipulations have demonstrated developmental and systems-level effects. Lesion studies have demonstrated effects on trace tone acquisition. Unfortunately, because a comprehensive and systematic approach has rarely been taken, no unifying picture is presently available of the role of cholinergic systems in aversive conditioning. One major problem is the lack of studies that look at a range of learning and memory processes: Inhibitory avoidance procedures have proven very productive for assessing the effect of posttraining cholinergic manipulations on performance, but very few inhibitory avoidance studies have assessed effects on acquisition or retrieval. Also of concern is the lack of consistency following posttraining muscarinic antagonist treatment in Pavlovian fear conditioning studies. A systematic, parametric approach may be required to determine why these treatments block consolidation of cued and contextual fear in some procedures and not others. The complexities obtained with cholinergic manipulations are at least partly due to the fact that cholinergic neurotransmission modulates the functions of the amygdala, cortex, and hippocampus, each of which plays different roles in various forms of aversive conditioning.

The study of cholinergic involvement in learning and memory is of great importance for understanding the basic neurobiology of these processes and in developing treatments for neurodegenerative disorders, cognitive impairment and aging. 
Aversive conditioning provides an efficient, tractable and welldescribed set of procedures for examining this involvement. Further research and the development of new neurobiological techniques will allow continued expansion of our understanding of the roles of acetylcholine transmission in learning and memory.

\section{REFERENCES}

Anagnostaras, S.G., Maren, S., and Fanselow, M.S. 1995. Scopolamine selectively disrupts the acquisition of contextual fear conditioning in rats. Neurobiol. Learn. Mem. 64: 191-194.

.1999a. Temporally graded retrograde amnesia of contextual fear after hippocampal damage in rats: Within-subjects examination. $J$. Neurosci. 19: 1106-1114.

Anagnostaras, S.M., Maren, S., Sage, J.R., Goodrich, S., and Fanselow, M.S. 1999b. Scopolamine and Pavlovian fear conditioning in rats: Dose-effect analysis. Neuropsychopharmacology 21: 731-744.

Anagnostaras, S.G., Murphy, G.G., Hamilton, S.E., Mitchell, S.L., Rahnama, N.P., Nathanson, N.M., and Silva, A.J. 2003. Selective cognitive dysfunction in acetylcholine M1 muscarinic receptor mutant mice. Nat. Neurosci. 6: 51-58.

Baldi, E., Ambrogi Lorenzini, C., Sacchetti, B., Tassoni, G., and Bucherelli, C. 2000. Effects of coupled perirhinal cortex and medial septal area, fimbria-fornix, entorhinal cortex tetrodotoxin inactivations on passive avoidance consolidation in the rat. Neurosci. Lett. 280: 91-94.

Bammer, G. 1982. Pharmacological investigations of neurotransmitter involvement in passive avoidance responding: A review and some new results. Neurosci. Biobehav. Rev. 6: 247-296.

Baratti, C.M., Huygens, P., Mino, J., Merlo, A., and Gardella, J. 1979. Memory facilitation with post-trial injection of oxotremorine and physostigmine in mice. Psychopharmacology 64: 85-88.

Baxter, M.G., Bucci, D.J., Gorman, L.K., Wiley, R.G., and Gallagher, M. 1995. Selective immunotoxic lesions of basal forebrain cells: Effects on learning and memory in rats. Behav. Neurosci. 109: 714-722.

Bernal, M.C., Vicens, P., Carrasco, M.C., and Redolat, R. 1999. Effects of nicotine on spatial learning in C57BL mice. Behav. Pharmacology 10: $333-336$.

Blozovski, D. and Dumery, V. 1987. Development of amygdaloid cholinergic mediation of passive avoidance learning in the rat. II Nicotinic mechanisms. Exp. Brain Res. 67: 70-76.

Bovet, D., Bovet-Nitti, F., and Oliverio, A. 1966. Effects of nicotine on avoidance conditioning of inbred strains of mice. Psychopharmacologia 10: 1-5.

Cahill, L. and McGaugh, J.L. 1990. Amygdaloid complex lesions differentially affect retention of tasks using appetitive and aversive reinforcement. Behav. Neurosci. 104: 532-543.

.1998. Mechanisms of emotional arousal and lasting declarative memory. Trends Neurosci. 21: 294-299.

Calderone, B.J., Duman, C.H., and Picciotto, M.R. 2000. Fear conditioning and latent inhibition in mice lacking the high affinity subclass of nicotinic acetylcholine receptors in the brain. Neuropharmacology 39: 2779-2784.

Cangioli, I., Baldi, E., Mannaoini, P.F., Bucherelli, C., Blandian, P., and Passani, M.B. 2002. Activation of histaminergic H3 receptors in the rat basolateral amygdala improves expression of fear memory and enhances acetylcholine release. European J. Neurosci. 16: $521-528$.

Caulfield, M.P., Higgins, G.A., and Straughan, D.W. 1983. Central administration of the muscarinic receptor subtype-selective antagonist pirenzipine selectively impairs passive avoidance learning in the mouse. J. Pharmacy Pharmacol. 35: 131-135.

Conner, J.M., Culbertson, A., Packowski, C., Chiba, A.A., and Tuszynski, M.H. 2003. Lesions of the basal forebrain cholinergic system impair task acquisition and abolish cortical plasticity associated with motor skill learning. Neuron 38: 819-829.

Dalmaz, C., Introini-Collison, I.B., and McGaugh, J.L. 1993. Noradrenergic and cholinergic interactions in the amygdala and the modulation of memory storage. Behav. Brain Res. 58: 167-174.

Davis, M. 1992. The role of the amygdala in conditioned fear. In The amygdala: Neurobiological aspects of emotion, memory and mental dysfunction (ed. J.P. Aggleton), pp. 255-306. Wiley Liss, New York.

Eidi, M., Zarrindast, M.-R., Eidi, A., Oryan, S., and Parivar, K. 2003. Effects of istamine and cholinergic systems on memory retention of passive avoidance learning in rats. European J. Pharmacol. 465: $91-96$.

Everitt, B.J. and Robbins, T.W. 1997. Central cholinergic systems and cognition. Annu. Rev. Psych. 48: 649-684.

Fanselow, M.S. and LeDoux, J.E. 1999. Why we think plasticity underlying Pavlovian fear conditioning occurs in the basolateral amygdala. Neuron 23: 229-232.

Fendt, M. and Fanselow, M.S. 1999. The neuroanatomical and neurochemical basis of conditioned fear. Neurosci. Biobehav. Rev. 23: 743-760.

Ferreira, T.L., Moreira, K.M., Ikeda, D.C., Bueno, O.F.A., and Oliveira, M.G.M. 2003. Effects of dorsal striatum lesions in tone fear conditioning and contextual fear conditioning. Brain Res. 987: $17-24$.

Fornari, R.V., Moreira, K.M., and Oliveira, M.G.M. 2000. Effects of the selective M1 muscarinic receptor antagonist dicyclomine on emotional memory. Learn. Mem. 7: 287-292.

Fransen, E., Alonso, A.A., and Hasselmo, M.E. 2002. Simulations of the role of the muscarinic activated calcium-sensitive nonspecific cation current INCM in entorhinal neuronal activity during delayed matching tasks. J. Neurosci. 22: 1081-1097.

Gale, G.D., Anagnostaras, S.M., and Fanselow, M.S. 2001. Cholinergic modulation of Pavlovian fear conditioning: Effects of intra-hippocampal scopolamine infusion. Hippocampus 11: 371-376.

Gale, G.D., Anagnostaras, S.G., Godsil, B.P., Mitchell, S., Nozawa, T. Sage, J.R., Wiltgen, B., and Fanselow, M.S. 2004. The basolateral amygdala and storage of fear memories spanning the adult lifetime of rats. J. Neurosci. (in press).

Giordano, M. and Prado-Alcala, R.A. 1986. Retrograde amnesia produced by post-training injection of atropine into the caudate-putamen: Protective effect of the negative reinforcer. Pharmaco. Biochem. Behav. 24: 905-909.

Giachetti, A., Giraldo, E., Ladinsky, E., and Montagna, E. 1986. Binding and functional profiles of the selective M1 muscarinic receptor antagonists trihexyphenidyl and dicyclomine. Brit. J. Pharmacol. 89: 83-90.

Glick, S.D., Marsanico, R.G., and Greenstein, S. 1974. Differential recovery of function following hippocampal, caudate and septal lesion in mice. J. Compar. Physiol. Psych. 86: 787-792.

Gould, T.J. and Wehner, J.M. 1999. Nicotine enhancement of contextual fear conditioning. Behav. Brain Res. 102: 31-39.

Gould, T.J. and Higgins, J.S. 2003. Nicotine enhances contextual fear conditioning in C57BL/6J mice at 1 and 7 days post-training. Neurobiol. Learn. Mem. 80: 147-157.

Greba, Q., Munro, L.J., and Kokkinidis, L. 2000. The involvement of ventral tegmental area cholinergic muscarinic receptors in classically conditioned fear expression as measured with fear-potentiated startle. Brain Res. 870: 135-141.

Han, C.J., O'Tuathaigh, C.M., van Tright, L., Quinn, J.J., Fanselow, M.S., Mongeau, R., Koch, C., and Anderson, D.J. 2003. Trace but not delay fear conditioning requires attention and the anterior cingulate cortex. Proc. Natl. Acad. Sci. 100: 13087-13092.

Hasselmo, M.E. 1999. Neuromodulation: Acetylcholine and memory modulation. Trends Cogn. Sci. 3: 351-359.

Haycock, J.W., Deadwyler, S.A., Sideroff, S.I., and McGaugh, J.L. 1973. Retrograde amnesia and cholinergic systems in the caudate-putamen complex and dorsal hippocampus. Exp. Neurol. 41: 201-213.

Helmstetter, F.J. and Bellgowan, P.S. 1994. Effects of muscimol applied to the basolateral amygdala on acquisition and expression of contextual fear conditioning in rats. Behav. Neurosci. 108: $1005-1009$.

Introini, I.B. and Baratti, C. 1984. The impairment of retention induced by $\beta$-endorphin in mice may be mediated by a reduction in central cholinergic activity. Behav. Neural Biol. 41: 152-163.

Introini-Collison, I.B., Dalmaz, C., and McGaugh, J.L. 1996. Amygdala $\beta$-noradrenergic influences on memory consolidation involve cholinergic activation. Neurobiol. Learn. Mem. 65: 57-64.

Izquierdo, I., da Cunha, C., Rosat, R., Jerusalinsky, D., Ferreira, M.B., and Medina, J.H. 1992. Neurotransmitter receptors involved in post-training memory processing by the amygdala, medial septum, and hippocampus of the rat. Behav. Neural Biol. 58: $16-26$

Jeruzalinsky, D., Cervenansky, C., Walz, R., Bianchin, M., and Izquierdo, I. 1993. A peptide muscarinic toxin from the Green Mamba venom shows agonist-like action in an inhibitory avoidance learning task. European J. Pharmacol. 240: 103-105.

Killcross, S., Robbins, T.W., and Everitt, B.J. 1997. Different types of fear-conditioned behaviour mediated by separate nuclei within amygdala. Nature 388: 377-380.

Kim, J.J. and Fanselow, M.S. 1992. Modality-retrograde amnesia of fear. Science 256: 675-677.

King, S.L., Marks, M.J., Grady, S.L., Caldarone, B.J., Koren, A.O., Mukhin, A.G., Collins, A.C., and Picciotto, M.R. 2003. Conditional expression in corticothalamic efferents reveals a developmental role for nicotinic acetylcholine receptors in modulation of passive avoidance behavior. J. Neurosci. 23: 3837-3843.

\section{Learning \& Memory}


LeDoux, J.E., Iwata, J., Cicchetti, P., and Reis, D.J. 1988. Different projections of the central amygdaloid nucleus mediate autonomic and behavioral correlates of conditioned fear. J. Neurosci. 8: 2517-2529.

Lee, H.J., Choi, J.S., Brown, T.H., and Kim, J.J. 2001. Amygdalar NMDA receptors are critical for the expression of multiple conditioned fear responses. J. Neurosci. 21: 4116-4124.

Lehmann, H., Treit, D., and Parent, M.B. 2003. Spared anterograde memory for shock-probe fear conditioning after inactivation of the amygdala. Learn. Mem. 10: 261-269.

Levin, E.D. 2002. Nicotinic receptor subtypes and cognitive function. $J$. Neurobiol. 53: 633-640.

Mallet, P.E., Beninger, R.J., Flesher, S.N., Jhamandas, K., and Boegman, R.J. 1995. Nucleus basalis lesions: Implication of the basoamygdaloid cholinergic pathways in memory. Brain Res. Bull. 36: 51-56.

Maren, S. 2003. What the amygdala does and doesn't do in aversive learning. Learn. Mem. 10: 306-308.

Maren, S. and Fanselow, M.S. 1995. Synaptic plasticity in the basolateral amygdala induced by hippocampal formation stimulation in vivo. $J$. Neurosci. 15: 7548-7564.

.1996. The amygdala and fear conditioning: Has the nut been cracked? Neuron 16: 237-240.

Maren, S., Aharonov, G., and Fanselow, M.S. 1996a. Retrograde abolition of conditional fear after excitotoxic lesions in the basolateral amygdala of rats: Absence of a temporal gradient. Behav. Neurosci. 110: 718-726.

Maren, S., Aharonov, G., Stote, D.L., and Fanselow, M.S. 1996b. $\mathrm{N}$-Methyl-D-aspartate receptors in the basolateral amygdala are required for both acquisition and expression of conditional fear in rats. Behav. Neurosci. 110: $1365-1374$.

Martinez, I., Quirarte, G.L., Diaz-Cintra, S., Quiroz, C., and Prado-Alcala, R.A. 2002. Effects of lesions of hippocampal fields CA1 and CA3 on acquisition of inhibitory avoidance. Neuropsychobiology 46: 97-103.

McAlonan, G.M., Wilkinson, L.S., Robbins, T.W., and Everitt, B.J. 1995. The effects of AMPA-induced lesions of the septo-hippocampal cholinergic projection on aversive conditioning to explicit and contextual cues and spatial learning in the water maze. European J. Neurosci. 7: 281-292.

McGaugh, J.L. 1966. Time dependent processes in memory storage. Science 153: 1351-1358.

McGaugh, J.L., Cahill, L., and Roozendaal, B. 1996. Involvement of the amygdala in memory storage: Interaction with other brain systems. Proc. Natl. Acad. Sci. 93: 13508-13514.

McGaugh, J.L., Cahill, L., Ferry, B., and Roozendaal, R. 2000. Brain systems and the regulation of memory consolidation. In Brain, perception, memory: Advances in cognitive neuroscience (ed. J.J. Bolhuis). Oxford University Press, London.

Mello e Souza, T., Vianna, M.R.M., Rodrigues, J., Quevedo, J., Moleta, B.A., and Izquierdo, I. 2000. Involvement of the medial precentral prefrontal cortex in memory consolidation for inhibitory avoidance learning in rats. Pharmacol. Biochem. Behav. 66: 615-622.

Meyers, B. 1965. Some effects of scopolamine on a passive avoidance response in rats. Psychopharmacologia 8: 111-119.

Miyakawa, T., Yamada, M., Duttaroy, A., and Wess, J. 2001. Hyperactivity and intact hippocampus-dependent learning in mice lacking the M1 muscarinic acetylcholine receptor. J. Neurosci. 21: $5239-5250$.

Muller, J., Corodimas, K.P., Friedel, Z., and LeDoux, J.E. 1997. Functional inactivation of the lateral and basal nuclei of the amygdala by muscimol infusion prevents fear conditioning to an explicit conditioned stimulus and to contextual stimuli. Behav. Neurosci. 111: 683-691.

Oliverio, A. 1966. Effects of mecamylamine on avoidance conditioning and maze learning of mice. J. Pharmacol. Exp. Therapeutics 54: $350-356$.

Parent, M. and McGaugh, J.L. 1994. Posttraining infusions of lidocaine into the amygdala basolateral complex impairs retention of inhibitory avoidance training. Brain Res. 661: 97-103.

Parent, M., Tomaz, C., and McGaugh, J.L. 1992. Increased training in an aversively motivated task attenuates the memory impairing effects of post-training $N$-methyl-D-aspartate acid-induced amygdala lesions. Behav. Neurosci. 106: 791-799.

Parent, M., West, M., and McGaugh, J.L. 1994. Memory of rats with amygdala lesions induced 30 days after footshock-motivated escape training reflects degree of original training. Behav. Neurosci. 6: $1080-1087$.

Parent, M., Avila, E., and McGaugh, J.L. 1995. Footshock facilitates the expression of aversively motivated memory in rats given post-training amygdala basolateral complex lesions. Brain Res. 676: $235-244$.
Passani, M.B., Cangioli, I., Baldi, E., Bucherelli, C., Mannaioni, P.F., and Blandina, P. 2001. Histamine H3 receptor-mediated impairment of contextual fear conditioning and in vivo inhibition of cholinergic neurotransmission in basolateral amygdala. European J. Neurosci. 14: $1522-1528$.

Paylor, R., Nguyen, M., Crawley, J.N., Patrick, J., Beaudet, A., and Orr-Urtreger, A. 1998. $\alpha-7$ nicotinic receptor subunits are not necessary for hippocampal-dependent learning or sensorimotor gating: A behavioral characterization of Acra7-deficient mice. Learn. Mem. 5: 302-316.

Phillips, J.E. and LeDoux, J.E. 1992. Differential contribution of amygdala and hippocampus to cued and contextual fear conditioning. Behav. Neurosci. 106: 274-285.

Picciotto, M.R., Zoli, M., Lena, C., Bessis, A., Lallemand, Y., Le Novere, N., Vincent, P., Merlo Pich, E., Brulet, P., and Changeux, J.-P. 1995. Abnormal avoidance learning in mice lacking functional high-affinity nicotine receptor in the brain. Nature 374: 65-67.

Poincheval-Fuhrman, S. and Sara, S.J. 1993. Chronic nicotine ingestion improves radial arm maze performance in rats. Behav. Pharmacol. 4: $535-539$.

Power, A.E. and McGaugh, J.L. 2002. Phthalic acid amygdalopetal lesion of the nucleus basalis magnocellularis induces reversible memory deficits in rats. Neurobiol. Learn. Mem. 77: 372-388.

Power, A.E., Thal, L.J., and McGaugh, J.L. 2002. Lesions of the nucleus basalis magnocellularis with 192 IgG-saporin block memory enhancement with posttraining norepinephrine in the basolateral amygdala. Proc. NY Acad. Sci. 99: 2315-2319.

Power, A.E., Vazdarjanova, A., and McGaugh, J.L. 2003. Muscarinic cholinergic influences in memory consolidation. Neurobiol. Learn. Mem. 80: 178-193.

Prado-Alcala, R.A. 1995. Serial and parallel processing during memory consolidation. In Plasticity in the central nervous system: Learning and memory (ed. J.L. McGaugh), pp. 57-65. Erlbaum, Hillsdale, NJ.

Prado-Alcala, R.A., Grinberg, Z.J., Arditti, Z.L., Garcia, M.M., Prieto, H.G., and Brust-Carmona, H. 1975. Learning deficits produced by chronic and reversible lesions of the corpus striatum in rats. Physiol. Behav. 15: 283-287.

Prado-Alcala, R.A., Fernandez-Ruiz, J., and Quirarte, G. 1993. Cholinergic neurons and memory. In Synaptic transmission 2 (ed. T.W. Stone), pp. 57-69. Taylor and Francis, London.

Prado-Alcala, R.A., Ruiloba, M.I., Rubio, L., Solana-Figeroa, R., Medina, C., Salado-Castillo, R., and Quirarte, G.L. 2003a. Regional infusions of serotonin into the striatum and memory consolidation. Synapse 47: 169-175.

Prado-Alcala, R.A., Solana-Figueroa, R., Galindo, L.E., Medina, A.C., and Quirarte, G.L. 2003b. Blockade of striatal 5HT-2 receptors produces retrograde amnesia in rats. Life Sci. 74: 481-488.

Quinn, J.J., Oommen, S.S., Morrison, G.E., and Fanselow, M.S. 2002. Post-training excitotoxic lesions of the dorsal hippocampus attenuate forward trace, backward trace, and delay fear conditioning in a temporally specific manner. Hippocampus 12: 495-504.

Riekkinen, P., Kuitunen, J., and Riekkinen, M. 1995. Effects of scopolamine infusions into the anterior and posterior cingulate on passive avoidance and water maze navigation. Brain Res. 685: 4654.

Roesler, R., Schroder, N., Vianna, M.R.M., Quevedo, J., Bromberg, E., Kapczinski, F., and Ferreira, M.B.C. 2003. Differential involvement of hippocampal and amygdalar NMDA receptors in contextual and aversive aspects of inhibitory avoidance memory in rats. Brain Res. 975: $207-213$

Roldan, G., Bolanos-Badillo, E., Gonzalez-Sanchez, H., Quirarte, G.L. and Prado-Alcala, R.A. 1997. Selective M1 muscarinic receptor antagonists disrupt consolidation of inhibitory avoidance in rats. Neurosci. Lett. 230: 93-96.

Rudy, J.W. 1996. Scopolamine administered before and after training impairs both contextual and auditory-cue fear conditioning. Neurobiol. Learn. Mem. 65: 73-81.

Sacchetti, B., Baldi, E., Lorenzini, C.A., and Bucherelli, C. 2002. Differential contribution of some cortical sites to the formation of memory traces supporting fear conditioning. Exp. Brain Res. 146: $223-232$.

. 2003. Role of the neocortex in consolidation of fear conditioning memories in rats. Exp. Brain Res. 152: 323-328.

Salado-Castillo, R., Diaz del Guante, M.A., Alvarado, R., Quirarte, G.L., and Prado-Alcala, R.A. 1996. Effects of regional GABAergic blockade of the striatum on memory consolidation. Neurobiol. Learn. Mem. 66: $102-108$.

Schafe, G.E., Thiele, T.E., and Bernstein, I.L. 1998. Conditioning method dramatically alters the role of amygdala in taste aversion learning. Learn. Mem. 5: 481-492.

Schauz, C. and Koch, M. 1999. Lesions of the nucleus basalis 
Tinsley et al.

magnocellularis do not impair prepulse inhibition and latent inhibition of fear-potentiated startle in the rats. Brain Res.

815: $98-105$.

Solana-Figueroa, R. and Prado-Alcala, R.A. 1990. Retrograde amnesia produced by intra-striatal atropine and its reversal by choline. Life Sci. 46: 679-686.

Solana-Figueroa, R., Salado-Castillo, R., Galindo, L.E., Quirarte, G.L., and Prado-Alcala, R.A. 2002. Effects of pre-training intra-striatal administration of $p$-chloroamphetamine on inhibitory avoidance. Neurobiol. Learn. Mem. 78: 178-185.

Stewart, C., Burke, S., and Marrocco, R. 2001. Cholinergic modulation of covert attention in the rat. Psychopharmacology 155: 210-218.

Swanson, L.W. and Petrovich, G.D. 1998. What is the amygdala? Trends Neurosci. 21: 323-331.

Szyndler, J., Sienkiewicz-Jarosz, H., Maciejak, P., Siemiatkowski, M., Rokicki, D., Czlonkowska, A.I., and Plaznik, A. 2001. The anxiolytic-like effect of nicotine undergoes rapid tolerance in a model of contextual fear conditioning in rats. Pharmacol. Biochem. Behav. 69: 511-518.

Vianna, M.R.M., Izquierdo, L.A., Barros, D.M., de Souza, M.M., Rodrigues, C., Sant'Anna, M.K., Medina, J.H., and Izquierdo, I. 2001. Pharmacological differences between memory consolidation of habituation to an open field and inhibitory avoidance learning. Brazilian J. Med. Biol. Res. 34: 233-240.

Wallenstein, G.V. and Vago, D.R. 2001. Intra-hippocampal scopolamine impairs both acquisition and consolidation of contextual fear conditioning. Neurobiol. Learn. Mem. 75: 245-252.

Warburton, D.M., Wesnes, K., Shergold, K., and James, M. 1986. Facilitation of learning and state dependency with nicotine. Psychopharmacology 89: 55-59.

White, N.M. and Salinas, J.A. 2003. Mnemonic functions of dorsal striatum and hippocampus in aversive conditioning. Behav. Brain Res. 142: 99-107.

Winocur, G. and Mills, J.A. 1969. Effects of caudate lesions on avoidance behavior in rats. J. Compar. Physiol. Psych. 68: 552-557.

Worms, P., Gueudet, C., Perio, A., and Soubrie, P. 1989. Systemic injection of pirenzipine induces a deficit in passive avoidance learning in rats. Psychopharmacology 98: 286-288.

Young, S.L., Bohenek, D.L., and Fanselow, M.S. 1994. NMDA processes mediate anterograde amnesia of contextual fear conditioning induced by hippocampal damage: Immunization against amnesia by contextual preexposure. Behav. Neurosci. 108: 19-29.

Zarrindast, M.-R., Sadegh, M., and Shafaghi, B. 1996. Effects of nicotine on memory retrieval in mice. European J. Pharmacol. 295: 1-6.

Zhang, Z.J., Berbos, T.G., Wrenn, C.C., and Wiley, R.G. 1996. Loss of nucleus basalis magnocellularis, but not septal, cholinergic neurons correlates with passive avoidance impairment in rats treated with 192-saporin. Neurosci. Lett. 203: 214-218.

\section{Learning \& Memory}




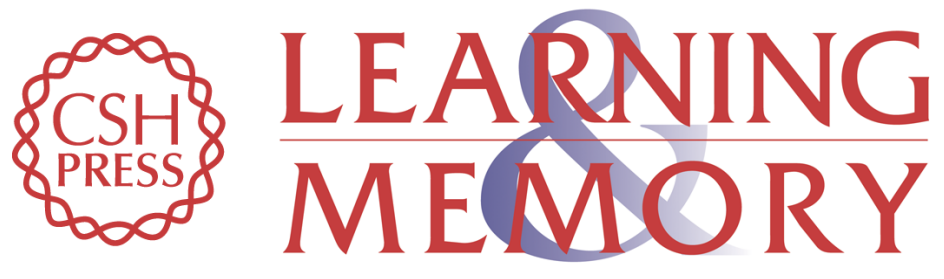

\section{The Role of Muscarinic and Nicotinic Cholinergic Neurotransmission in Aversive Conditioning: Comparing Pavlovian Fear Conditioning and Inhibitory Avoidance}

Matthew R. Tinsley, Jennifer J. Quinn and Michael S. Fanselow

Learn. Mem. 2004, 11:

Access the most recent version at doi:10.1101/lm.70204

References This article cites 99 articles, 17 of which can be accessed free at:

http://learnmem.cshlp.org/content/11/1/35.full.html\#ref-list-1

License

Email Alerting Receive free email alerts when new articles cite this article - sign up in the box at the Service top right corner of the article or click here. 